\title{
A NEW APPROACH TO THE MIDDLE EAST CONFLICT: THE ANALYTIC HIERARCHY PROCESS
}

\author{
H.J. Zoffer* \\ Dean Emeritus and \\ Professor of Business Administration \\ University of Pittsburgh \\ E-mail: zoffer@katz.pitt.edu \\ T.L. Saaty \\ Distinguished University Professor \\ University of Pittsburgh \\ E-mail: saaty@katz.pitt.edu
}

\begin{abstract}
In most long-lasting conflicts, each party's grievances increase while the concessions they are willing to make decline in number, quality, and perceived value. Both parties lose sight of what they are willing to settle for, generally exaggerate their own needs, and minimize the needs of the other side over time. But, it is precisely the matter of trading that needs to be made more concrete and of higher priority for both sides, if a meaningful resolution is to be found. Without a formal way of trading off the concessions and packages of concessions, both sides are likely to suspect that they are getting the short end of the bargain. All of this requires going beyond verbal descriptions of the concessions to more broadly include their economic, social, geographic, humanitarian and historical worth. It is critical that all of this needs to be translated into priorities derived in terms of the different values and beliefs of the parties. The Analytic Hierarchy Process (AHP) provides a way to perform such an assessment with the participation of negotiators for the parties. It is a positive approach that makes it possible to reason and express feelings and judgments with numerical intensities to derive priorities. With the assistance of panels of Israeli participants and Palestinian participants brought together in 2009 and 2010, AHP was applied for the first time to the Palestinian-Israeli conflict. AHP makes it possible to evaluate moderate and extreme viewpoints and determine their effect on the trading of concessions.
\end{abstract}

Keywords: Middle East Conflict, AHP, decision making process.

\section{Introduction}

We present an alternative process to address the Israeli Palestinian conflict. It does so in two ways that are different from past efforts. The first is by formally structuring the conflict and the second is the manner in which discussions are conducted and conclusions drawn. The approach will help create a solution to the conflict and provide negotiators with a unique pathway to consider the thorny issues and corresponding concessions underlying the deliberations, together with their implementation. Among the prior contentious issues addressed by this process and encouraged by governments and major participants in the conflicts were the difficult confrontations in South Africa and in Northern Ireland. The outcomes of this process added valuable dimension to the discussions and resolutions of those problems.

\footnotetext{
${ }^{*}$ Corresponding author
} 
The Middle East conflict is a prolonged and interminable struggle between parties deeply committed to unyielding positions related to identity, religion and territory. Understanding the Israeli-Palestinian conflict necessitates the recognition that both parties believe there is a theological bond between their people and the land. In addition, all three major religions recognize Jerusalem as symbolic of their belief in a one god idea.

The severity of this conflict has intensified in our life-time because international events have catapulted the Middle East into a crucial position in the world's search for peace. Claims are made by these peoples of their right to have a state that ensures their group identity. The problem is greatly compounded by great power rivalries, weapon sales, interference by neighboring countries, economic and social discrepancies and the threat of nuclear retaliation. Although it is possible that the global framework might accelerate a solution, in fact, it complicates the solution due to the apparent insolvability of the issues. Hence, a solution continues to elude the global community.

Some of the world's best negotiators, diplomats and able leaders have grappled with the resolution of this conflict. However, despite their best efforts, the current condition continues to torment all the parties. Since the inception of the Analytic Hierarchy Process and its generalization to dependence and feedback, the Analytic Network Process (ANP), authors have conducted numerous case studies (that suggest the method as an alternative approach to conflict resolution that will lay bare the structure of the problem and allow reasoned judgment to prevail.

\section{Developing a Comprehensive Approach}

One might ask: Why is it that so many distinguished politicians and negotiators have failed to reach consensus after sixty years of trying? Here are some possible reasons:

1. They had no way to measure the importance and value of intangible factors which can dominate the process.

2. They had no overall unifying structure to organize and prioritize issues and concessions.

3. They had no mechanism to trade off concessions by measuring their worth.

4. They had no way to capture each party's perception of the other side's benefits and costs.

5. They had no way to provide confidence to the other party that they were not gaining more than that party

6. They had no way to avoid the effect of intense emotions and innuendoes which negatively affect the negotiation process.

7. They had no way to test the sensitivity and stability of the solution to changes in their judgments with respect to the importance of the factors that determined the best outcome.

It is not a coincidence that the Analytic Hierarchy Process addresses each of these reasons in a comprehensive and deliberate way, thus eliminating many of the obstructions for moving forward to identify an equitable final solution.

\section{The Process}

The AHP is about breaking a problem down and then aggregating the solutions of all the sub-problems into a conclusion. It facilitates decision making by organizing perceptions, feelings, judgments, and memories into a framework that exhibits the forces that influence a decision. In the simple and most common case, the forces are arranged from the more general and less controllable to the more specific and controllable. The AHP is based on the innate human ability to make sound judgments about small problems and also about large problems when a structure like a hierarchy can be built to represent the 
influences involved. It has been applied in a variety of decisions and planning projects in nearly 40 countries.

Briefly, we see decision making as a process that involves the following steps:

(1) Structure a problem with a model that shows the problem's key elements and their relationships

(2) Elicit judgments that reflect knowledge, feelings, or emotions of the primary parties, as well as all other parties that have influence on the outcome

(3) Represent those judgments with meaningful numbers

(4) Use these numbers to calculate the priorities of the elements of the hierarchy

(5) Synthesize these results to determine an overall outcome

(6) Analyze sensitivity to changes in judgment

The retributive conflict resolution approach presented here takes into consideration the benefits to A from concessions by B and the costs to A of the return concessions A makes, as well as A's perception of the benefits to B from the concessions A makes, and also A's perception of the costs to B of the concessions B makes. A similar consideration is made for B. Findings from this exercise suggest that the development of "bundles" of concessions may minimize the difference in ratios of gains and losses between the two parties that a negotiator can use as a tool to move the resolution process forward.

The expressed objectives of the study were:

- To identify the issues, major and minor and to examine the relative significance or priority of the issues currently inhibiting solution of the Israeli-Palestinian conflict

- To share knowledge and insights about the current Israeli - Palestinian situation from differing points of view

- To construct a comprehensive model of the situation

- To explore the benefits and costs of alternative courses of action

The traditional approach involving diplomacy and face to face negotiations has led to an inconclusive outcome, partially attributable to attitudes colored by strong emotions on both sides. Our approach attempts to address the impact of negative attitudes by focusing the participants on making judgments that measure the intensity of their perceptions about the influences that each of the issues brings to bear upon the final outcome.

In this study we consider each party's list of issues, which if addressed by the other party by making concessions, would provide sufficient benefit to that side towards meeting their goal. They, in turn, would be willing to make concessions to the other side to balance those concessions with an equivalent tradeoff. We refer to these issues as criteria. The process consists of taking a set of concessions from one side and measuring them against these criteria in terms of actual or perceived benefits to the other side. Actual benefits (or costs) are defined as judgments by one party about the relative importance of the concessions they receive (or give). Perceived benefits (or costs) are defined as putting oneself in the shoes of the other side to estimate the benefits (or costs), even though that side may have a totally different opinion about what the concessions received or offered are worth.

The remainder of this work is structured as follows: First, we define the problem in general terms. Subsequently we outline the structure of the decision in the form of multiple hierarchies. This effect is evaluated by the parties according to their value systems, both actual and perceived. The outcomes of this analysis are priorities used to assess ratios of gains and losses by both sides that make it possible to determine those concessions for which each party's gains exceed its losses and these gains to losses are not unacceptably large for either party in comparison with the other party. Then we examine and identify 
ratios that are nearly equal for the two sides from the concessions made, and pose questions about the viability of such bundles of concessions that are traded off. Finally we suggest a way for moving the process to the next level through better definition of the issues and concessions as well as through recognition of potential implementation policies and other relevant changes.

\section{Implementing the Process}

In the opening day of each three day meeting the panel brainstormed the issues and structured the problem, defined the parties at interest and developed a series of concessions that each party might offer to the other.

The process was not without conflict and negotiation of its own. At times, the panel made judgments without agreement on exact definitions. There was nearly always unanimous agreement on the nature of the conflict, with much debate about the underlying concerns. These concerns differed according to which constituent group was putting them forward. For example, among the Palestinian key constituents are Palestinian refugees, Hamas followers, Fatah followers, Palestinians who still live in Israel and Diaspora Palestinians. Among the Israeli constituents are the ultra right orthodox community, Israelis living in settlements in the West Bank, those associated with the Likud movement, those associated with the Labor Party, and those more actively seeking peace as a primary objective, without dwelling on the details of the difficulties to achieve it.

Since the beginning of the conflict, different constituents have proposed many different approaches. These approaches inevitably influenced the panel's perception of the concessions to be made by either side. In fact, one participant suggested that it would be difficult "to think outside the box." He thought that the group was so influenced by previous thinking that they would have difficulty in conceptualizing 'creative' alternatives that had not been proposed previously.

The panels defined the goal as an attempt to understand what forces and influences or combinations thereof would tend toward a consensus peace accord for the conflict between Israel and the Palestinians. To accomplish this goal, the panels of nine individuals were assembled to represent a cross section of thinking on both sides. Their members had present or prior experience in academia, government and in business. However, it was recognized that the panels did not represent a complete cross-sample of opinions. The sample of panel participants was not sufficiently large to include all points of view nor was it intended to be so because of limitations of time and resources.

This initiative only sought to test the AHP methodology on a problem that had previously evaded resolution. The size of the panels was thought to be sufficient to account for the different populations. However, it was agreed that the work is exploratory in nature and intended to demonstrate how the method can be used over a short period of time to arrive at a process that moves the negotiation process forward.

As mentioned above, at no point in the development and evaluation of the problem was the process easy. In fact, even the "purpose" was not easily agreed upon and at several points in the three days over which the meetings took place, the panel readdressed what the undertaking was intended to accomplish. It looked at the purpose of the project from various perspectives in the hope of finding one that appeared more promising than others that have been tried. The panel brainstormed all the issues they could think of that had to be considered in the framework. Listing the issues made it easier to identify the concessions, and to structure the problem. Taking time to structure the problem in as comprehensive a fashion as may be feasible, is a crucial first step before attempting to prioritize the relative importance of its constituent parts that have causal influence on the concessions and actions to be taken. Needless to say, the structure that emerged in the early discussion depended on the parties, their knowledge, experience and conditioning. In a strict sense it was a political rather than a scientific structure. 
The exercise in discussing specific issues sometimes seemed to generate incompatible perceptions of what can and would be achievable in peace negotiations. For example, all the Israelis present were adamant that a one state solution is impossible to contemplate, while Palestinians all agreed that a solution that does not grant refugees their internationally recognized rights to return is also impossible to contemplate. But we do know that historically adamant positions have changed when circumstances change. For proper application of the AHP methodology, it is important to include in the structure all factors, including those that some participants feel are so crucial to their preconceived and predetermined positions, that any concession on those issues seems inconceivable.

In order to develop the necessary measurements for prioritization, we need to calculate the gains and losses for each concession from each of the parties. The panel developed a total of eight hierarchies involving benefits and costs and perceived benefits and costs: four hierarchies for the Israeli group and four hierarchies for the Palestinian group. The exercise in which 106 issues were identified through the process of brainstorming served as a stimulus to the thinking of the participants to deal with the structuring process. Each of the eight hierarchies involves a goal, for example, Israel's Benefits from Palestinian Concessions, and a set of criteria that are a subset of the issues relevant to that goal. They are called criteria in terms of which all the possible concessions that were identified were evaluated by scoring them one at a time. The criteria that were developed for these eight models were chosen by each of the Israeli and Palestinian participants respectively. Because of the volume of issues, we found it necessary in developing the hierarchies to select as criteria a subset of the most crucial issues. The overall goal of each of the corresponding criteria in the four hierarchies involved the apparent equalization of the ratio of the gains to the losses by each side.

\section{Discussion: The gain to loss ratios of concessions made by both sides need to be close to one another}

One of the key takeaways that all participants in the exercise appreciated was that they learned more about the other party. One of the primary challenges to the approach turned out to be the same item that created a greater depth in understanding: a lack of common definitions. A lack of common definitions challenged the participants to actively engage in deeper understanding of each other. For future exercises of this sort though, we suggest that one of the first steps to pursue is to define terms and language. For instance, one of the concessions that is offered is to direct more effort to "Human Rights". How the parties define 'human rights', however, differs greatly. Even though philosophically there should be an easily determined common definition for "human rights", the reality is that the parties took different positions on this issue.

The judgment and prioritization process for the concessions was implemented for each party without knowledge of the other party.

The object is to make the ratios of the two parties close. Each party can by itself estimate the gain to loss ratio of its opponent and determine if his gain to loss ratio is much greater than the other party's gain to loss ratio. That also makes the negotiations more difficult. The original model sought a solution that matched the best one-to-one concession. However, given that the best solution was a standoff, we found that one had to consider trading off bundles of concessions. The role of the mediator is extremely important in this setting. There are two ways that the mediator can help to alter the outcome of ratios. Both the numerator and the denominator of the ratio includes perceptions of the other; in the numerator is what one party perceives the cost of concessions are to the adversary; whereas the denominator includes what one party perceives the other party's benefits. It is interesting to note that in a retributive conflict one party perceives the costs to the adversary as a benefit to itself and conversely the gain to the adversary as a loss to itself. The mediator has a real opportunity to bridge gaps, given the measured 
difference between the two parties and their varying perceptions, interpretations and respect for "international" law.

Our results underline the differences between the Israelis and the Palestinians. In particular, the findings highlight the value of the Israelis' concessions as measured by the Palestinians when compared with the Palestinians' concessions as measured by the Israelis through the large differences in ratios. Given this disparity, there is great opportunity by one party to take a leadership role in the resolution process. Moreover, there is an even greater opportunity for a mediator to help bridge the gap in the gain-to-loss ratios. By educating both parties on the true costs and benefits to the adversary, the perceptions are brought more in line with reality and the score differences minimized. It is possible that external influences or pressures might be necessary to rationalize the difference in the gain-to-loss ratios in order to recognize the discrepancies.

\section{Equalizing Concession Trade-Offs}

Mistrust and the inclination to act retributively prevent people from making all their concessions at once. To determine the fairest and maximum gain to both parties from concessions being traded off, we computed gain-loss ratios for each pair of concessions, one for each party. These gain-loss ratios represent the gain to one party from the concession made by the other party, divided by that party's loss from the concession it made. The gain to one party's concession is obtained as the benefits accrued from the other party's concession multiplied by the perceived costs to the party making the concession. The loss to one party's concession is obtained as the costs of the concession it made multiplied by the perceived benefits to the other party. To make the tradeoffs, we considered only pairs of concessions with gain-loss ratios for both parties greater than one. This means that either side would be reluctant to trade-off a concession in return for another from which its gain is less than its loss.

The tradeoff process started by attempting to trade-off single concessions with two objectives in mind: closeness of the gain-to-loss ratios and maximization of the ratio. If there were no single concessions that could be traded that satisfied both criteria to ensure fairness, then groups of concessions were considered for tradeoff to satisfy the same requirements.

The outcome shows that with the exception of two concession, one related to the resettlement of Palestinian refugees and the acceptance of Israel by the Palestinians as a secure, independent, and democratic Jewish state, all the other concessions can be traded off either singly or in groups against other concessions without violating the constrains previously established, namely that the gain-loss ratios be not too large and as close to one another as possible. One might question the advantage of trading off all of the concession identified to date without addressing the two major issues mentioned above. Prior negotiations have been hampered by the chaos or confusion caused by trying to address all of the issues at the same time. What this process permits is eliminating either temporarily or permanently any discussion that would impede attention to the two major matters that seem the most acrimonious and potentially irreconcilable. Another reason to take care of the tradable issues first is to give the parties experience in interacting successfully with one another, thus engendering a spirit of trust which could be very helpful when the final few but crucially important issues are considered. For example, the Israeli concession, "Shared Administration of Resources" trades off against the Palestinian concession "Drop Opposition to Trade and Normal Relations with Israel" with a resulting gain-loss ratio for both sides of about 1.03 . Similarly, the remaining concessions are traded off against those of the other side in groups of two and three. The final two Israeli concessions do not tradeoff against the last Palestinian concession. 


\section{REFERENCES}

Zoffer, H. J., A. Bahurmoz, M. K. Hamid M. Minutolo and T. L. Saaty, Synthesis of Complex Criteria Decision Making: A Case Towards a Consensus Agreement for a Middle East Conflict Resolution, Group Decision and Negotiation, 17: 363-385, 2008.

Saaty, T.L., and H.J. Zoffer, Negotiating The Israeli-Palestinian Controversy From A New Perspective, International Journal of Information Technology and Decision Making, Volume 10, Issue 1, 2011. 